\title{
Penyusunan Rancangan Kebutuhan Aplikasi Pembelajaran di Sekolah Menengah Atas Melalui Pendekatan PAR
}

\author{
M.J. Dewiyani Sunarto*, Tan Amelia, Tri Sagirani, Julianto Lemantara1), Bambang Hariadi2) \\ 1) Fakultas Teknologi dan Informatika Universitas Dinamika, 2)Fakultas Desain dan Industri \\ Kreatif \\ e-mail: dewiyani@dinamika.ac.id, meli@dinamika.ac.id,tris@dinamika.ac.id, \\ julianto@dinamika.ac.id, bambang@dinamika.ac.id \\ *Penulis Korespondesi: E-mail : dewiyani@dinamika.ac.id
}

\begin{abstract}
The positive impact of the Covid-19 Pandemic is the development of online learning at almost all levels of education. In its implementation, online learning requires a learning application. For the learning application to accommodate the needs of educators, of course, it must be built based on the needs of educators, which are explored using the Participatory Action Research (PAR) Method, in which the proposer places himself as an insider, not as an outsider. In preparing this design, the educators involved are representatives of high school teachers (SMA). The results obtained are the design of high school level learning applications, with a learning model that follows the needs of educators and students, easy, and can be used anywhere, guaranteeing quality standards without reducing the freedom of educators to develop material. After the learning application design is obtained, the educator is asked to fill out a questionnaire to know the suitability of the application design made with the educator's need. The results obtained from the questionnaire to the respondents from the teacher showed that the approved application design was followed by making learning applications. The advice given is that the activity is continued in making application design and implementation in schools.
\end{abstract}

Keywords: Learning Applications, PAR Methods, Senior High School

\begin{abstract}
Abstrak
Dampak positif dari Pandemi Covid-19 adalah berkembangnya pembelajaran online di hampir semua jenjang pendidikan. Dalam pelaksanaannya, sebuah pembelajaran online memerlukan sebuah aplikasi pembelajaran. Agar aplikasi pembelajaran dapat mewadahi kebutuhan pendidik, maka tentunya harus dibangun berdasar kebutuhan pendidik, yang dijajagi dengan menggunakan Pendekatan Participatory Action Research (PAR), di mana pengusul menempatkan diri sebagai insider dan bukan sebagai outsider. Pada penyusunan desain ini, pendidik yang terlibat adalah perwakilan guru Sekolah Menengah Atas (SMA). Hasil yang didapat adalah desain aplikasi pembelajaran jenjang SMA, dengan model pembelajaran yang bersesuaian dengan kebutuhan pendidik dan peserta didik, mudah dan dapat digunakan di manapun, menjamin standar mutu tanpa mengurangi kebebasan pendidik untuk mengembangkan materi. Setelah desain aplikasi pembelajaran didapatkan, maka pendidik diminta untuk mengisi kuesioner agar diketahui kesesuaian desain aplikasi yang dibuat dengan kebutuhan pendidik. Hasil yang didapat dari angket kepada responden dari guru menunjukkan bahwa desain aplikasi disetujui diterima untuk dilanjutkan dengan pembuatan rancang bangun aplikasi pembelajaran. Saran yang diberikan adalah kegiatan dilanjutkan pada pembuatan rancang bangun aplikasi dan implementasi di sekolah.
\end{abstract}

Kata kunci: Aplikasi Pembelajaran, Metode PAR, Sekolah Menengah Atas

\section{PENDAHULUAN}

Pembelajaran online di Indonesia selama setahun terakhir telah mengalami banyak kemajuan karena didorong oleh terhalangnya proses belajar mengajar secara tatap muka akibat pandemi covid-19. Berbagai bentuk pembelajaran online telah dilakukan oleh 
pendidik untuk tetap menjalankan proses belajar mengajar sebaik mungkin, dari bentuk yang paling sederhana, misalnya grup WhattsApp dengan perangkatnya, seperti chat, lampiran video, file sampai pada hal yang sudah lebih mumpuni seperti penggunaan web conferences (Google Meet, Zoom dan lain-lain), bahkan sampai penggunaan Open Broadcast Sofware (OBS) agar tampak lebih menarik dan mudah dipahami oleh peserta didik (Sunarto, 2021). Meskipun demikian, pada kenyataannya masih terdapat banyak ketidaksiapan terutama dari pendidik maupun lembaga pendidikan, untuk menghadirkan pembelajaran online secara utuh, terutama adanya kendala kesenjangan kesediaan jaringan, bantuan aplikasi yang mendukung dan kebijakan pembelajaran seperti penyesuaian model pembelajaran, perangkat pembelajaran dan lain sebagainya (Soudien, 2020). Banyak lembaga pendidikan yang tidak mempunyai kemampuan untuk mengatasi ketidaksiapan tersebut, sehingga memerlukan dukungan dari lembaga pendidikan pada tingkat yang lebih tinggi untuk mengatasinya, karena sejatinya hal tersebut merupakan tantangan yang jika diselesaikan, dunia pendidikan akan selangkah lebih maju (Hughes, 2020). Beberapa usaha telah dilakukan untuk meningkatkan mutu pembelajaran online di tingkat sekolah menengah, diantaranya pelatihan pembuatan blog di sebuah SMP (Sitompul et al., 2021) dengan tujuan agar melengkapi bahan ajar bagi peserta didik. Sementara (Erpidawati \& Novelti, 2021), selain Blog, juga menambahkan dengan pelatihan Google Drive dengan sasaran Pengawas Sekolah, agar dapat mengaplikasikan google drive dan blog sebagai media pendukung dan pengetahuan baru. Dalam bidang bahasa bagi anak-anak, dengan tujuan untuk membantu peserta didik untuk lebih cepat dan menyenangkan dalam mempelajari kosa kata Bahasa Inggris melalui sebuah aplikasi, maka dilatihlah anak dengan level Pendidikan Anak Usia Dini (PAUD) untuk menggunakan aplikasi pembelajaran tersebut (Budiharto et al., 2021), sedang (Agustina Pali, Finsensius Mbabho, 2021) menciptakan metode Joyful Learning untuk mempermudah belajar Bahasa Inggris di Sekolah Dasar . Selain itu, pelatihan mengenai Learning Management System juga telah diberikan untuk mendukung pembelajaran dalam jaringan (Kurniawan et al., 2021), dan pendidik menunjukkan kemampuannya untuk menghasilkan kelas hebat meskipun tanpa tatap muka. Pada bidang evaluasi pembelajaran, (Pagarra et al., 2020) telah mengenalkan sarana test online berupa quizziz untuk mempermudah pendidik memberikan evaluasi pembelajaran kepada peserta didiknya. Dalam bidang pembelajaran musik yang seolah sangat sulit jika tidak bertatap mukapun, telah diusahakan oleh (Usman et al., 2020) untuk menciptakan e-learning dan mampu mendorong peserta didik ke arah potensi maksimalnya.

(Sunarto, 2021) menyatakan bahwa sejatinya pembelajaran online memiliki tiga unsur utama yaitu, mengandalkan internet sebagai sarana pembelajaran, menggunakan model pembelajaran tertentu, serta adanya aplikasi pembelajaran untuk mewadahi perangkat pembelajaran yang bersesuaian dengan model pembelajarannya. Dalam penerapan penelitian kali ini, akan lebih difokuskan pada pembuatan aplikasi pembelajaran yang bersesuaian dengan model pembelajaran. Ragam aplikasi pembelajaran yang ada di dunia pendidikan saat ini memang sangat banyak, mulai dari aplikasi pembelajaran tingkat dunia seperti Moodle, Edmodo, sampai buatan anak negeri, seperti Ruang Guru. Peringkat teratas menurut (Yildiz et al., 2018) adalah pada Moodle. Memang para pendidik dapat menggunakan baik yang berbayar maupun sampai yang dapat digunakan secara gratis (open source) berbagai macam aplikasi pembelajaran tersebut, namun pendidik sering mengeluhkan bahwa aplikasi pembelajaran tersebut tidak serta merta mewadahi kebutuhan pendidik. Misalnya ada kalanya suatu menu yang penting bagi mereka, tidak terdapat pada aplikasi tersebut, atau sebaliknya sering pada aplikasi tersebut malah terdapat menu yang tidak pernah digunakan oleh pendidik. Hal ini dapat dimaklumi, karena sebagaian besar aplikasi pembelajaran memang hanya melakukan desain secara umum 
sesuai kebutuhan dunia pendidikan. Namun, pendidik menginginkan adanya suatu aplikasi yang memenuhi kebutuhan pendidik untuk melakukan proses belajar mengajar dengan baik, meski di saat pandemi yang membuat pendidik dan peserta didik tidak dapat bertemu muka.

Solusi dari masalah yang ada, dan sekaligus menjadi pembeda dari aplikasi pembelajaran yang telah ada adalah pada fitur atau menu yang diciptakan didasarkan pada kebutuhan pendidik, sehingga pendidik yang diwakili oleh Musyawarah Guru Mata Pelajaran (MGMP) akan merasa lebih mudah menggunakannya, karena memang berdasarkan permintaan pendidik, yaitu berdasar pengalaman real dalam menghadapi proses belajar mengajar di setiap harinya. Pada artikel penerapan kepada masyarakat kali ini, akan lebih ditekankan terlebih dahulu pada proses untuk mengetahui kebutuhan pendidik untuk mewadahi perangkat ajar yang telah disiapkan dan dituangkan dalam aplikasi pembelajaran yang akan dibuat.

\section{METODE PELAKSANAAN}

Agar tujuan untuk menciptakan aplikasi pembelajaran yang sesuai dengan kebutuhan pendidik dapat tercapai, maka metode yang digunakan adalah metode Participatory Action Research (PAR). Metode ini merupakan metode yang bersumber pada pendekatan paradigma partisipatoris yaitu artinya, menempatkan pendidik yang dalam hal ini diwakili oleh Musyawarah Guru Mata Pelajaran (MGMP) sebagai subjek dalam proses kegiatan. Pengusul menempatkan diri sebagai insider (pihak yang berada di dalam kelompok sasaran dan turut aktif di dalam program kegiatan), bukan sebagai outsider (pihak yang berada di luar kelompok sasaran).

Metode PAR sendiri telah digunakan dalam berbagai penerapan, dan terbukti membuahkan hasil yang baik, karena identifikasi rumusan masalah penelitian berdasar kepada subjek yang diteliti (Suyanto, 2018; Muhtarom, 2019; Rahmat \& Mirnawati, 2020 ).

(Pain et al., 2011) menyatakan terdapat 7 langkah yang harus dijalankan dengan menggunakan pendekatan PAR. Berikut ini akan dijabarkan ketujuh langkah tersebut dan implementasinya.

Langkah 1 : Kolaborasi

Langkah ini merupakan langkah awal, pengusul menentukan terlebih dahulu siapa kelompok masyarakat terpilih, yang dapat mewakili kebutuhan proses pembelajaran yang dapat mewadahi kepentingan pendidik dan peserta didik. Berdasar kesadaran bahwa kebutuhan aplikasi harus bersifat general, maka pengusul memutuskan untuk berkoordinasi dengan MGMP, dengan pertimbangan bahwa MGMP merupakan wadah dari seluruh guru SMA di bawah naungan Dinas Pendidikan Provinsi Jawa Timur. MGMP sering mengadakan koordinasi antar anggota dan saling berbagi pengetahuan untuk kemajuan bersama. Setelah didapat perwakilan MGMP, maka pengusul mulai merencanakan pembagian peran dengan kelompok terpilih dengan tidak melupakan kerjasama secara aktif untuk mencapai tujuan bersama. Pada tahap ini, telah disepakati bersama, bahwa tugas dari pengusul adalah (i) Menyiapkan instumen untuk mengenal kebutuhan pendidik dalam proses mengajar, (ii) menarik kesimpulan dari langkah (i), (iii) mempresentasikan hasil penarikan kesimpulan kepada pendidik, kemudian meminta masukan kembali jika masih ada yang kurang benar dan diulang sampai pendidik menyatakan setuju, (iv) berkoordinasi dengan pembuat aplikasi dan berfungsi sebagai narahubung antara pendidik dan pembuat aplikasi. Sedang tugas dari pendidik adalah (i) menyampaikan sejelas-jelasnya kebutuhan pembelajaran yang akan dituangkan di aplikasi, (ii) Memberikan masukan terhadap kesimpulan, desain dan aplikasi yang dibuat oleh pengusul . 
Langkah 2 : Menentukan Prinsip Dasar Penyusunan Teori

Pengusul dan pendidik pada langkah ini menentukan dasar penyusunan teori yang akan melandasi penyusunan aplikasi pembelajaran ini, karena dengan landasan teori atau yang lebih dikenal dengan model pembelajaran, tentu akan menghasilkan aplikasi pembelajaran dengan bentuk yang berbeda. Usulan dari pendidik pada mulanya berbedabeda, mulai dari Problem Based Learning, Contextual Teaching Learning, Discovery Learning dan lain sebagainya. Setelah menimbang karakteristik kebutuhan pembelajaran abad 21 dan menyelaraskan dengan model belajar generasi saat ini, maka dipilihlah model pembelajaran Inquiry (Penemuan) untuk mendasari penyusunan aplikasi pembelajaran ini. Langkah 3 : Penentuan Pemberi Keputusan

Pada langkah ini, harus ditentukan pemberi keputusan, jika terdapat masalah yang tidak dapat diselesaikan. Pemberi keputusan adalah person yang mempunyai kepakaran atau pengambil kebijakan lebih dari pengusul atau pendidik. Pada usulan pengabdian masyarakat kali ini, ditetapkan sebagai pengambil keputusan adalah Kepala Dinas Pendidikan Provinsi Jawa Timur, karena kepala dinaslah yang menetapkan arah kebijakan proses belajar di provinsi Jawa Timur.

Langkah 4 : Menentukan Etika Penamaan

Etika penamaan yang dimaksud adalah, apakah pendidik yang ditunjuk diantara kelompok pendidik yang tergabung dalam MGMP, berkenan untuk disebutkan secara terbuka atau tidak. Pada pengusulan pengabdian masyarakat ini, pendidik bersedia untuk disebutkan secara terbuka, bahkan mendapatkan surat tugas khusus dari Dinas Pendidikan Provinsi Jawa Timur.

Langkah 5 : Membangun Teori

Setelah diadakan beberapa kali pertemuan dan pembahasan, maka didapatkan rangkuman kebutuhan proses belajar mengajar berbasis model Inquiry, beserta rencana aplikasi yang dapat memenuhi kebutuhan proses belajar mengajar. Uraian lebih detail dapat dilihat bagian hasil dan pembahasan.

Langkah 6 : Aksi

Pada langkah aksi ini, ditentukan langkah dan jadwal yang disepakati bersama. Selain itu pihak pengambil keputusan, yaitu Kepala Dinas Pendidikan telah memutuskan aplikasi akan digunakan pada seluruh mata pelajaran di tingkat SMA di provinsi Jawa Timur. Langkah 7 : Evaluasi

Evaluasi akan dilakukan tahap demi tahap dari langkah pada pendekatan PAR ini, sehingga ketika terdapat kesalahan, segera akan diperbaiki.

\section{HASIL dan PEMBAHASAN}

Hasil yang dipaparkan di sini adalah hasil dari langkah 5 metode PAR, yaitu membangun teori agar dihasilkan suatu aplikasi yang dapat mewadahi kebutuhan pendidik, dan berlandaskan model pembelajaran Inquiry, yang merupakan model pembelajaran yang dirasa penting untuk menghadapai Era Revolusi Industry 5.0 saat ini (Jerrim et al., 2020).

Aplikasi yang dihasilkan, telah disepakati untuk mempunyai beberapa kebutuhan agar dapat menunjang proses belajar mengajar dengan baik, yaitu seperti tercantum pada tabel 1 sampai 4.

Tabel 1. Kebutuhan Aplikasi untuk Menunjang Metode Inquiry

\begin{tabular}{ll}
\hline \multicolumn{1}{c}{ Item } & \multicolumn{1}{c}{ Penjelasan } \\
\hline Platform & $\begin{array}{l}\text { Akan dibuat aplikasi dengan dua platform, yaitu Web } \\
\text { dan Android. Hal ini disepakati dengan menyesuaikan } \\
\text { peralatan yang dimiliki baik oleh pendidik maupun }\end{array}$ \\
\hline
\end{tabular}


peserta didik. Tidak dibuat versi IOS karena tidak banyak yang menggunakan.

Menu yang muncul di Web dan Android akan dibedakan, karena memikirkan kenyamanan, terutama pada saat akses di Android.

a. Menu di Web : Semua menu akan tampil di Web

b. Menu di Android :

- MGMP dapat mengakses :materi kompetensi, materi MGMP, dan materi yang diunggah guru, menampilkan ujian, forum diskusi yang memiliki channel, dan pengumuman.

- Guru dapat mengakses : materi MGMP, materi guru, buat tugas, diskusi kelas, dan menampilkan soal ujian.

- Siswa dapat mengakses : materi MGMP, menampilkan materi guru, forum diskusi, dan menampilkan daftar tugas yang diberikan oleh guru.

- Musyawarah Guru Mata Pelajaran (MGMP). MGMP mempunyai prioritas tertinggi dalam aplikasi ini, artinya MGMP dapat memantau semua kegiatan belajar mengajar pada bidang studi nya. Selain itu peran MGMP sangat dominan, karena merupakan penentu apakah materi dari pendidik yang diunggah sudah layak untuk dikonsumsi peserta didik. Hal ini dilakukan, agar kualitas bahan ajar yang diunggah oleh guru terjaga. Selain itu, MGMP juga mempunyai bahan ajar yang dapat dibaca oleh seluruh pendidik yang tergabung dalam MGMP tersebut, dan dapat digunakan sebagai bahan wajib maupun pengayaan. Jadi MGMP berperan sebagai penyedia data dan mengatur kelas.

- Guru. Guru dapat membuat bahan ajar maupun ujian, namun hanya dapat diakses oleh peserta didik yang terdaftar di kelas nya. Aplikasi yang dibangun pada sisi pendidik memiliki fungsi sebagai penyedia muatan lokal atau tambahan yang akan diberikan pada peserta didik di kelasnya serta membuat dan mengatur tugas dan ujian untuk peserta didik.

- Siswa. Aplikasi MoLearn pada sisi peserta didik memiliki fungsi sebagai tempat mengambil materi, mengumpulkan tugas, dan juga mengerjakan ujian serta berdiskusi dengan teman kelas dan juga gurunya.

(Tan Amelia, M.J. Dewiyani Sunarto, Bambang Hariadi, Tri Sagirani, Julianto Lemantara, Budi Jatmiko, 2019a, 2019b) 
Tabel 2. Menu untuk MGMP Versi Web dan Android

\begin{tabular}{|c|c|}
\hline Item & Penjelasan \\
\hline $\begin{array}{l}\text { Menu untuk MGMP } \\
\text { versi Web }\end{array}$ & 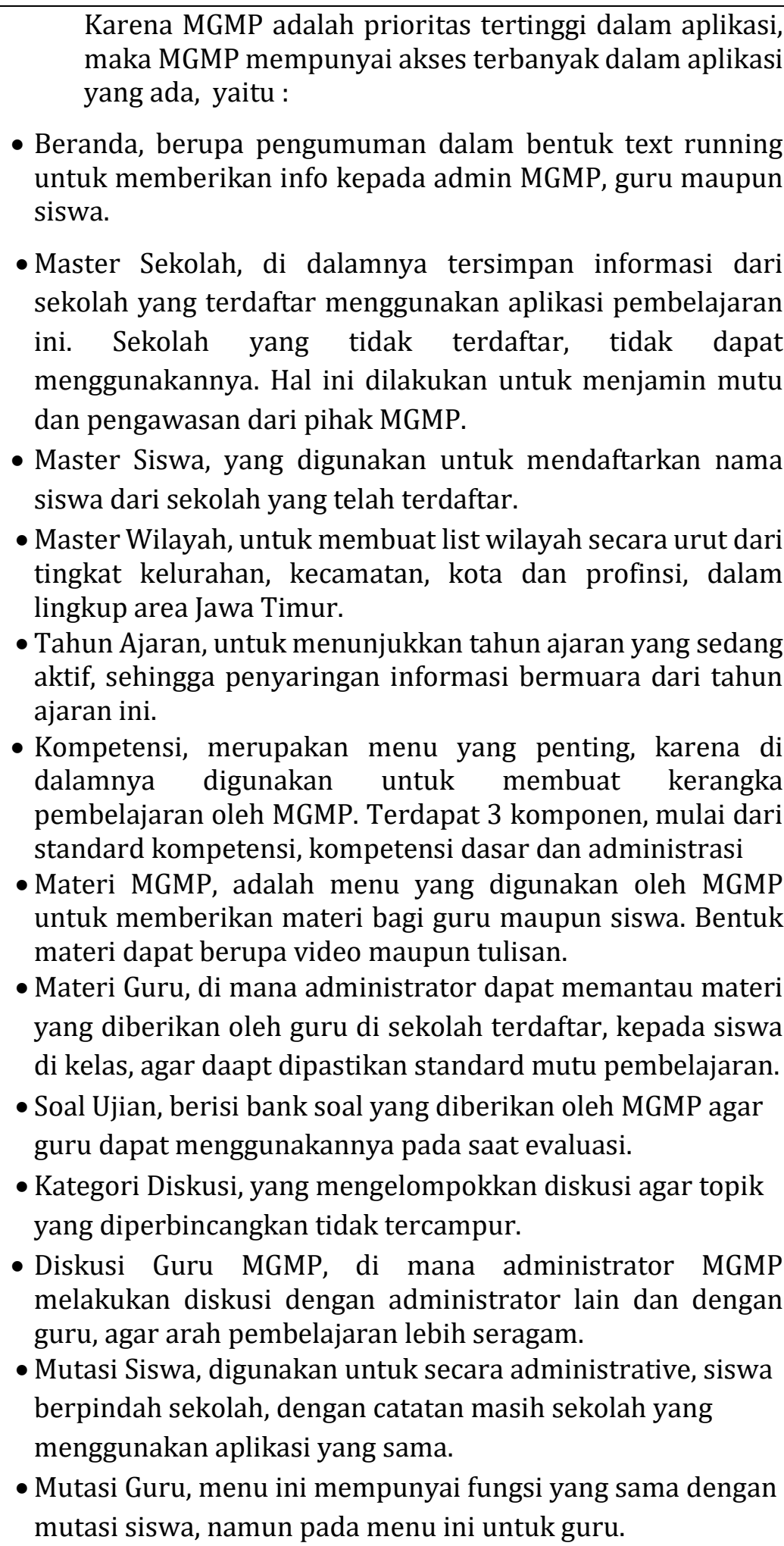 \\
\hline
\end{tabular}




Item Penjelasan

- Group User, menu ini digunakan oleh administrator, yaitu tingkatan tertinggi, untuk menentukan kewenangan pengguna aplikasi.

- User, digunakan untuk menambah atau merubah data pengguna.

- Registrasi Guru, untuk memvalidasi pengguna baru yang baru saja bergabung.

(Tan Amelia, M.J. Dewiyani Sunarto, Bambang Hariadi, Tri Sagirani, Julianto Lemantara, Budi Jatmiko, 2019a, 2019b)

Menu MGMP versi • Materi Kompetensi. Karena secara prinsip pada versi Android Android adalah hanya untuk melihat, maka menu ini digunakan untuk menampilkan kompetensi yang telah didaftarkan oleh MGMP.

- Materi MGMP, untuk melihat materi yang telah diunggah melalui versi web. Sekali lagi, pada versi Android telah disepakati oleh perwakilan pendidik, hanya lebih dominan untuk melihat, karena pendidik merasa kesulitan jika harus menulis di Android.

- Materi yang diunggah Guru, secara sama dengan materi MGMP, hanya kali ini hasil dari unggahan guru.

- Menampilkan Ujian, digunakan untuk Admin MGMP untuk melihat soal ujian, agar dapat dipantau kesamaan tingkat kesulitan dan mutu.

- Forum diskusi, untuk berdisukusi oleh team MGMP agar dapat sesegera mungkin mengatasi masalah yang dihadapi, ataupun mengembangkan ilmu baru.

(Tan Amelia, M.J. Dewiyani Sunarto, Bambang Hariadi, Tri Sagirani, Julianto Lemantara, Budi Jatmiko, 2019a, 2019b)

Tabel 3. Menu untuk Guru Versi Web dan Android

\begin{tabular}{ll}
\hline \multicolumn{1}{c}{ Item } & \multicolumn{1}{c}{ Penjelasan } \\
\hline Menu Guru Versi & • Beranda, berupa pengumuman dalam bentuk text \\
& running untuk memberikan info kepada admin MGMP, \\
& guru maupun siswa. \\
& - Kelas Saya, digunakan oleh guru untuk menentukan \\
& kelas pada sebuah semester yang sedang diampu. \\
& $\bullet$ Kompetensi, dimanfaatkan oleh guru untuk melihat \\
& daftar standard kompetensi maupun kompetensi inti \\
& serta indicator yang telah disediakan oleh MGMP. \\
& - Materi MGMP, merupakan menu dimana guru dapat \\
& mengunduh materi yang telah disiapkan oleh MGMP. \\
& - Materi Guru, pada menu ini guru dapat \\
& mengembangkan materinya sendiri, selain materi dari \\
\hline
\end{tabular}


MGMP, sehingga dapat memberikan pengayaan kepada siswa. File dapat diberikan berupa teks atau tulisan, maupun video.

- Buat Tugas, pada menu ini, guru dapat memberikan tugas kepada siswa yang telah terdaftar di kelasnya, untuk kemudian dikumpulkan kembali pada aplikasi ini.

- Nilai Tugas, untuk melihat dan memberikan nilai pada tugas yang telah dikerjakan oleh siswa.

- Buat Ujian, merupakan menu dengan fungsi yang sama dengan membuat tugas, hanya kali ini untuk wadah bagi soal ujian. Pada menu ini, guru dapat memilih soal ujian dari bank soal yang telah dibuat oleh MGMP serta menjadwalkannya.

- Nilai Ujian, digunakan oleh guru untuk melihat kemudian memberikan penilaian atas jawaban siswa yang telah dibuat.

- Diskusi Kelas, menu ini dibuat khusus agar guru dapat berkomunikasi dengan siswa, tanpa harus menunggu bertemu di kelas, sehingga permasalahan siswa dapat segera teratasi.

- Diskusi Guru MGMP, menu ini sama dengan menu di MGMP

Menu ini digunakan guru dan juga oleh administrator untuk melakukan diskusi mengenai topik-topik yang sudah dibuat pada menu kategori diskusi.

- Buat Soal Ujian, di menu ini, guru dapat membuat soal untuk kelasnya sendiri, jika dirasa soal dari MGMP kurang.

(Tan Amelia, M.J. Dewiyani Sunarto, Bambang Hariadi, Tri Sagirani, Julianto Lemantara, Budi Jatmiko, 2019a, 2019b)
Menu Guru Versi
- Menampilkan materi MGMP. Karena versi Android, Android maka pada menu ini guru hanya dapat melihat materi yang diunggah oleh MGMP, sebagai materi yang dapat digunakan oleh guru di kelas.
- Materi Guru, pada menu ini, guru dapat melihat materi yang telah diunggah oleh guru itu sendiri untuk kelas yang diampunya.
- Buat Tugas, pada menu ini guru dapat membuat dan melihat tugas yang diberikan kepada siswa.
- Diskusi kelas, pada menu ini terbagi menjadi dua, yaitu diskusi dengan siswa dan diskusi dengan MGMP.
- Melihat Jawaban Ujian Siswa, pada menu ini, guru dapat melihat jawaban siswa, namun untuk dapat menilainya, guru harus menuju ke versi web. 
(Tan Amelia, M.J. Dewiyani Sunarto, Bambang Hariadi,

Tri Sagirani, Julianto Lemantara, Budi Jatmiko, 2019a, 2019b)

Tabel 4. Menu untuk Siswa Versi Web dan Android

Item Penjelasan

Menu Siswa Versi • Beranda, berupa pengumuman dalam bentuk text running Website untuk memberikan info kepada admin MGMP, guru maupun siswa.

- Materi MGMP, siswa dapat melihat materi yang dibuat oleh MGMP, sebagai materi wajib selain materi dari guru.

- Materi Guru, pada menu ini siswa yang telah tergabung pada kelas yang diampu oleh guru tertentu, dapat melihat materi tambahan dari guru masing-masing. Tentu saja, siswa kelas lain yang bukan diampu oleh guru tertentu, tidak dapat melihat materi ini.

- Tugas Kelas, pada menu ini siswa dapat melihat dan mengumpulkan tugas yang diberikan oleh guru pengampu.

- Ujian, sama dengan pada menu tugas kelas, maka pada menu ini siswa dapat melihat dan mengumpulkan jawaban ujian, serta nilai yang diberikan oleh guru.

- Diskusi Kelas, di mana pada menu ini, siswa dapat berdiskusi dengan teman sekelasnya maupun gurunya, namun tidak dapat berdiskusi dengan teman dari kelas lain maupun guru dari kelas lain.

Menu Siswa Versi Android
- Menampilkan materi MGMP, menu ini dapat digunakan oleh siswa untuk mengakses materi yang diunggah oleh MGMP melalui Android. Jadi siswa dapat menggunakan gadget nya untuk belajar.

- Menampilkan materi guru, hampir sama dengan materi MGMP, maka di sini siswa dapat mengunduh materi yang diberikan oleh guru di kelasnya untuk dipelajari, sebagai materi tambahan dari MGMP

- Forum Diskusi, siswa dapat berdiskusi dengan teman satu kelasnya melalui gadget nya, jika merasa ada masalah. Hal ini memupuk sifat kolaborasi antar siswa.

- Daftar Tugas, menampilkan daftar tugas yang diberikan oleh guru, siswa secara mudah melalui gadgetnya dapat melihat secara lengkap tugas yang diberikan oleh guru, jadwal pengumpulan, maupun status pengumpulan.

- Ujian Siswa, sama dengan tugas, namun digunakan untuk ujian.

(Tan Amelia, M.J. Dewiyani Sunarto, Bambang Hariadi, Tri Sagirani, Julianto Lemantara, Budi Jatmiko, 2019a, 2019b) 
Setelah rancangan kebutuhan seperti dipaparkan pada tabel 1 sampai 4 disepakati oleh perwakilan pendidik, maka untuk lebih meyakinkan akan hasil rancangan sebelum dibuat aplikasi yang sesungguhnya, diedarkan angket kepada 12 orang perwakilan pendidik. Gambaran karakteristik yang ingin dicapai adalah pada tampilan, manfaat, dan fungsi-fungsi yang digunakan, baik pada versi Web maupun Android telah layak disusun sebagai aplikasi pembelajaran.

Hasil dari angket berupa data kuantitatif yang berwujud angka-angka, dengan jenis skala pengukuran berupa skala interval, dengan mengurutkan mulai dari SS (sangat setuju) yang diberi skor 5 , S (setuju) diberi skor 4, N(netral) diberi skor 3, TS (tidak setuju) diberi skor 2, dan STS (sangat tidak setuju) diberi skor 1. Dipilihnya skala interval ini karena memang skala ini yang paling sering digunakan untuk mengukur gejala dalam penelitian sosial (Riduwan, 2019). Skala yang digunakan dalam pengukuran sikap pada penelitian ini adalah Skala Likert. Skala Likert digunakan untuk mengukur pendapat atau persepsi perwakilan pendidik terhadap rancangan aplikasi MoLearn berbasis Web dan Android. Dengan menggunakan skala Likert, maka variabel yang akan diukur dijabarkan menjadi dimensi, dimensi dijabarkan menjadi sub variabel, kemudian sub variabel dijabarkan lagi menjadi indikator yang dapat diukur. Akhirnya, indikator yang terukur ini dapat dijadikan titik tolak untuk membuat item instrumen yang berupa pertanyaan atau pernyataan yang perlu dijawab oleh responden (Riduwan, 2019). Instrumen kali ini disebarkan kepada 12 responden, yaitu perwakilan pendidik yang terlibat aktif dalam penyusunan rancangan ini, untuk memastikan bahwa rancangan yang dibuat telah sesuai dengan kebutuhan pendidik. Setelah terkumpul data, kemudian direkapitulasi. Rekapitulasi dilakukan dengan membuat skala interval seperti pada tabel 5

Tabel 5. Skala nilai pada item dan predikat

\begin{tabular}{cl}
\hline Skala nilai pada item & \multicolumn{1}{c}{ Predikat } \\
\hline $12-22$ & Sangat tidak setuju \\
$23-32$ & Tidak setuju \\
$33-42$ & Netral \\
$43-52$ & Setuju \\
$53-62$ & Sangat setuju \\
\hline
\end{tabular}

Dari hasil angket yang dilakukan, ternyata semua nilai masuk di range 43- 52, sehingga didapat hasil bahwa semua perwakilan pendidik setuju terhadap seluruh item yang dinilai rancangan yang akan dituangkan di Aplikasi Web dan Android. Ini berarti, rancangan aplikasi MoLearn baik versi web dan android, dinyatakan oleh perwakilan pendidik disetuju bahwa (1) tampilan rancangan menarik dan nyaman digunakan, (2) rancangan dapat memenuhi kebutuhan pembelajaran, serta (3) rancangan telah memenuhi syarat sebagai model pembelajaran yang memanfaatkan Teknologi Informasi.

\section{KESIMPULAN}

Dari hasil pembahasan bersama perwakilan pendidik dengan menggunakan metode PAR dapat disimpulkan, telah selesai dibuat rancangan aplikasi pembelajaran yang sesuai dengan kebutuhan pendidik. Setelah rancangan selesai disepakati bersama, akan dilanjutkan dengan pembuatan aplikasi. Aplikasi yang terjadi, bukan merupakan aplikasi yang umum seperti aplikasi pembelajaran lainnya, namun aplikasi yang sesuai dengan kebutuhan pendidik. Saran yang dapat diberikan adalah pada saat pembuatan Aplikasi Pembelajaran, setiap tahan pendidik harus tetap dilibatkan, agar tidak terjadi kesalahpahaman walau rancangan telah selesai dibuat. 


\section{UCAPAN TERIMAKASIH}

Terimakasih dan penghargaan yang setinggi-tingginya diucapkan kepada Dinas Pendidikan Provinsi Jawa Timur dan Perwakilan Pendidik di tingkat SMA yang telah bersedia terlibat dalam pembuatan rancangan aplikasi pembelajaran ini. Begitu banyak waktu yang dikorbankan oleh pendidik untuk mewujudkan rancangan ini, semoga selanjutnya dapat dihasilkan aplikasi yang dapat bermanfaat untuk kemajuan pendidikan di Indonesia, khususnya di Provinsi Jawa Timur.

\section{DAFTAR PUSTAKA}

Agustina Pali, Finsensius Mbabho, M. W. (2021). English for the Beginners di Era New Normal melalui Joyful Learning. Jurnal Publikasi Pendidikan, 11(1), 1-6.

Budiharto, R. A., Santoso, S. A., \& Lestari, R. A. (2021). Pengenalan English Vocabulary Pada Anak Usia Dini Melalui English For Kids. Dinamisia, 5(2), 287-293.

Erpidawati, \& Novelti. (2021). Pelatihan Pemanfaatan Teknologi Google Drive dan Blogs bagi Pengawas Sekolah Dasar. Dinamisia, 5(2), 330-334.

Hughes, C. (2020). COVID-19 and the opportunity to design a more mindful approach to learning. Prospects, 49(1-2), 69-72. https://doi.org/10.1007/s11125-020-09492-z

Jerrim, J., Oliver, M., \& Sims, S. (2020). Corrigendum to :The relationship between inquirybased teaching and students' achievement. New evidence from a longitudinal PISA study in England. Learning and Instruction (2019) 35 - 44. Learning and Instruction, 2019, 101309. https://doi.org/10.1016/j.learninstruc.2020.101309

Kurniawan, H., Susanti, E., \& Arriyani, N. (2021). Menjadi Guru yang Siap di masa Pandemi Covid-19 , Melalui Workshop Penggunaan Edmodo dan Google Classroom pada Pembelajaran Daring. Jurnal Publikasi Pendidikan, 11(1), 63-67.

Muhtarom, A. (2019). Participation Action Research dalam Membangun Kesadaran Pendidikan Anak di Lingkungan Perkampungan Transisi Kota. Dimas: Jurnal Pemikiran $\begin{array}{llll}\text { Agama Untuk Pemberdayaan, } 259 . & \end{array}$ https://doi.org/10.21580/dms.2018.182.3261

Pagarra, H., Bundu, P., Irfan, M., Hartoto, \& Raihan, S. (2020). Peningkatan Kompetensi Guru Dalam Mengevaluasi Pembelajaran Daring Menggunakan Aplikasi Berbasis Tes Dan Penugasan Online. Jurnal Publikasi Pendidikan, 10, 260-265. http://103.76.50.195/pubpend/article/view/16069

Pain, R., Whitman, G., \& Milledge, D. (2011). Participatory Action Research Toolkit: An Introduction to Using PAR as an Approach to Learning, Research and Action. Building Adaptive Strategies for Environmental Change with Land Use Managers, 1-8.

Rahmat, A., \& Mirnawati, M. (2020). Model Participation Action Research Dalam Pemberdayaan Masyarakat. Aksara: Jurnal Ilmu Pendidikan Nonformal, 6(1), 62. https://doi.org/10.37905/aksara.6.1.62-71.2020

Riduwan, D. (2019). Skala Pengukuran Variabel-Variabel Penelitian. (3rd ed.).

Sitompul, N. C., Leksono, I. P., \& Rejeki, H. W. (2021). Perancangan Blog Guru untuk Penyediaan Bahan Ajar di Era Pembelajaran Abad 21. Dinamisia, 5(2), 320-329.

Soudien, C. (2020). Complexities of difference and their significance for managing inequality in learning: Lessons from the COVID-19 crisis. Prospects, 49(1), 59-67.

Sunarto, M. J. D. (2021). Change Unplanned into Planned Online Learning: An Effort to Follow Health Protocols at an Information Technology College During the Covid-19 Pandemic Period. Studies in Learning and Teaching, 2(1), 16-28.

Suyanto, S. (2018). Membangun Kesadaran Sodaqoh Sampah Sebagai Model Pemberdayaan Masyarakat. Jurnal Pemberdayaan Masyarakat: Media Pemikiran Dan Dakwah Pembangunan, 1(2), 245. https://doi.org/10.14421/jpm.2017.012-02

Tan Amelia, M.J. Dewiyani Sunarto, Bambang Hariadi, Tri Sagirani, Julianto Lemantara, Budi 
Jatmiko, B. K. P. (2019a). URAIAN CIPTAAN PROGRAM KOMPUTER MOLEARN (ANDROID) V2. In Universitas Dinamika.

Tan Amelia, M.J. Dewiyani Sunarto, Bambang Hariadi, Tri Sagirani, Julianto Lemantara, Budi Jatmiko, B. K. P. (2019b). URAIAN CIPTAAN PROGRAM KOMPUTER MOLEARN (WEBSITE) V2. In Universitas Dinamika.

Usman, H., Pendidikan, P., Sekolah, G., Pendidikan, F. I., Makassar, U. N., \& Makassar, B. (2020). E-Learning Module Music In Pendidikan Guru Seokolah Dasar Fakultas Ilmu Pendidikan Universitas Negeri Makassar. Jurnal Publikasi Pendidikan, 10(1).

Yildiz, E. P., Tezer, M., \& Uzunboylu, H. (2018). Student opinion scale related to moodle LMS in an online learning environment: Validity and reliability study. International Journal of Interactive Mobile Technologies, 12(4), 97-108. https://doi.org/10.3991/ijim.v12i4.9205 